\title{
FLORNI SASTAV SUHOG TRAVNJAKA NA PODRUČJU RUDINE
}

\author{
Dinko Zima \\ Dr. sc., profesor visoke škole, Veleučilište u Požegi, Vukovarska 17, 34000 Požega, Hrvatska; \\ e-mail:dzima@vup.hr
}

\section{Edita Štefanić}

Dr. sc., redoviti profesor, Fakultet agrobiotehničkih znanosti Osijek, Vladimira Preloga 1, 31000 Osijek, Hrvatska; e-mail: estefanic@pfos.hr

\section{Vesna Kovačević}

Dr. sc., viši predavač, Veleučilište u Rijeci, Vukovarska 58, 51000 Rijeka, Hrvatska; e-mail:vesna.kovacevic@veleri.hr

\section{SAŽETAK}

Na blago valovitim istočnim obroncima Psunja razvijeni su suhi brdski travnjaci, koji predstavljaju jedan od najugroženijih oblika vegetacije, a bili su predmet ovog istraživanja. Teren je blago nagnut prema jugoistoku, južne je ekspozicije, nadmorska visina oko $400 \mathrm{~m}$. Cilj istraživanja bio je uturditi brojnost i raznolikost samonikle vaskularne flore travnjaka na području Rudine. Floristička istraživanja vršena su 2003., 2008., 2016. i 2017. godine. Na površini od oko 2500 m2 popisane su i determinirane biljne svojte, određena njihova pripadnost porodicama, flornim elementima i životnim oblicima. Zabilježeno je 186 biljnih svojti vaskularne flore unutar 46 porodica i 134 roda. Izvršena je taksonomska, ekološka i fitogeološka analiza. Taksonomska analiza ukazuje da golosjemenjača ima 2 vrste (1,08\%), dvosupnica 155 vrsta (83,33\%), a jednosupnica 29 vrsta (15,59\%). Analiza životnih oblika pokazuje da su najviše zastupljeni hemikriptofiti sa 113 vrsta (60,75\%) i terofiti s 29 vrsta $(15,59$ \%). U fitogeografskoj analizi dominiraju biljke euroazijskog flornog elementa sa 63 vrste $(33,87 \%)$ i biljke široke rasprostranjenosti s $38 \mathrm{vrsta}(20,43 \%$ ). Fitocenološka analiza florističkog sastava pokazuje da ovi travnjaci čine prijelazni položaj između razreda Festuco-Brometea i Molinio-Arrhenatheretea, odnosno da pokazuju prijelazni položaj između redova Festucetalia valesiacae, Brometalia erecti i Arrhenatheretalia.

Ključne riječi: Rudina, suhi travnjak, florni sastav 


\section{UVOD}

Kontinentalni suhi travnjaci tip su vegetacije koji se uglavnom sastoji od jednogodišnjih i višegodišnjih zeljastih biljnih vrsta, prvenstveno trava. Krstonošić et al. (2016) navode da su to biološki i krajobrazno vrlo vrijedna poluprirodna staništa, ubrajaju se među najugroženije tipove vegetacije u većem dijelu Europe te da su se njihove površine u posljednjih pedesetak godina značajno smanjile. Zima i Štefanić (2009a) navode da se suhi travnjaci ubrajaju među najugroženije tipove vegetacije, kako u našoj zemlji, tako i u Srednjoj i Zapadnoj Europi, a njihove su se površine u posljednjih pedesetak godina značajno smanjile. Suhi travnjaci u Republici Hrvatskoj, pa tako i u Požeškoj kotlini, spadaju u relativno rijetka staništa, te ih je potrebno očuvati u povoljnom stanju temeljem obveza preuzetih međunarodnim sporazumima, pogotovo stoga što ovi travnjaci predstavljaju floristički vrlo bogate površine. Jedan od suhih travnjaka u Požeškoj kotlini nalazi se neposredno uz srednjovjekovni lokalitet Rudina koji je smješten na nadmorskoj visini od 467 m, gdje se prostirala benediktinska opatija sv. Mihovila - Rudina, koja se spominje prvi put 1210 . godine. Arheološka istraživanja toga spomenika kulture vršena su u više navrata, a okolni blagi brežuljci, s obzirom na smještaj, upućuju na to da je područje bilo pogodno za poljoprivredne kulture, naročito za vinogradarstvo i voćarstvo, pa i stočarstvo. Područje Požeške kotline, kao i travnjak na lokalitetu Rudine, prostor je velike biološke raznolikosti, što je odraz velike ekološke raznolikosti toga područja te biogeografskog položaja Požeške kotline na raskrižju triju različitih biljnogeografskih, odnosno vegetacijskih utjecaja panonske šumostepske (aralo-kaspijske) zone (Aceri tatarici - Quercion), srednjoeuropske vegetacijske zone (Carpinion betuli) i submedieranske termofilne zone balkanskih hrastova (Quercion frainetto) (Ilijanić, 1977). Floru suhih travnjaka Požeške kotline istraživali su Kovačević (1974), Tomašević (1998a, 1998b, 2006), Zima (2008), Zima, Stefanic (2009a, 2009b) i Krstonošić et al. (2016). Florističkim istraživanjima Požeške kotline i okolnoga gorja do sada su zabilježene 1654 biljne vrste i podvrste (Tomašević, 2016). U posljednje vrijeme u Hrvatskoj je prisutan problem napuštanja tradicionalne poljoprivredne proizvodnje i migracija stanovništva u veće gradove te je izraženo napuštanje i zaraštanje travnjaka, čime su podložni sukcesiji i zarastanju, a to rezultira smanjenjem biološke i krajobrazne raznolikosti (Krstonošić et al., 2016), stoga ih je potrebno detaljnije istražiti.

Cilj istraživanja bio je utvrditi brojnost i raznolikost samonikle vaskularne flore travnjaka na području Rudine.

\section{MATERIJAL I METODE}

Istraživanja flore suhih travnjaka na području Rudine vršena su tijekom vegetacijskih sezona 2003., 2008. 2016. i 2017. godine, a obuhvaćena je šira zaravan uz samostan, na površini oko $2500 \mathrm{~m} 2$ i na rubnim, grmljem obraslim dijelovima. Teren je blago nagnut prema jugoistoku, južne ekspozicije, nadmorska visina oko $400 \mathrm{~m}$, pokrovnost oko $100 \%$, a podloga vapnenasto-laporasta. Biljne svojte su determinirane pomoću sljedećih florističkih djela: Domac (1994), Horvatić,Trinajstić (1967-1981), Trinajstić (1975-1986), Tutin et al., (1964-1980), Pignatti (1982), Josifović (1971-1976). Nomenklatura vrsta i porodica usklađena je prema Nikolić (2018), Tutin et al. (1964-1980). Porodice s pripadajućim rodovima i vrstama navedene su u popisu flore prema brojnosti vrsta unutar njih. 
Raspodjela u šest osnovnih životnih oblika izvršena je prema Horvat (1949), Šegulja (1977), Rauš, Šegulja (1983), a označeni su kako slijedi:

$$
\begin{array}{ll}
\mathrm{H}-\text { hemicryptophyta } & \mathrm{G}-\text { geophyta } \\
\mathrm{P}-\text { phanerophyta } & \mathrm{T}-\text { therophyta } \\
\mathrm{Ch}-\text { chamaephyta } & \mathrm{Hy}-\text { hydrophyta }
\end{array}
$$

Razvrstavanje biljaka po flornim elementima izvršeno je prema Horvatić (1963), Horvatić et al. (1967-1968), Šegulja (1977), Tutin et al. (1964-1980), Horvatić, Trinajstić (1967-1981), Trinajstić (1975-1986). Florni elementi su sljedeći:

1. Mediteranski florni element - medit

2. llirsko-balkanski florni element - ilbal

3. Južnoeuropski florni element - jeu

4. Atlantski florni element - at

5. Istočnoeuropsko-pontski florni element - ieup

6. Jugoistočnoeuropski florni element - jieu

7. Srednjoeuropski florni element - sredeu

8. Europski florni element - eu

9. Euroazijski florni element - euroaz

10. Biljke cirkumholarktičke rasprostranjenosti - cirkumhol

11. Biljke široke rasprostranjenosti - šir

12. Kultivirane i adventivne biljke - adv.

\section{REZULTATII RASPRAVA}

Rezultati florističkih istraživanja pokazuju da je na travnjaku Rudine zabilježeno 186 svojta vaskularne flore, što čini 11,2 \% od ukupno zabilježenih biljnih vrsta u Požeškoj kotlini (tablica 1).

Tablica 1. Vrste zabilježene na suhom travnjaku Rudina

\begin{tabular}{|llcc|}
\hline Naziv svojte & porodica & životni oblik & florni el. \\
\hline Achillea collina Becker ex Rchb & Asteraceae & $\mathrm{H}$ & sredeu \\
\hline Achillea pannonica Scheele & Asteraceae & $\mathrm{H}$ & euroaz \\
\hline Ambrosia artemisiifolia L. & Asteraceae & $\mathrm{T}$ & $\mathrm{adv}$ \\
\hline Anthemis tinctoria L. & Asteraceae & $\mathrm{H}$ & euroaz \\
\hline Artemisia vulgaris L. & Asteraceae & $\mathrm{H}$ & šir \\
\hline Bellis perennis L. & Asteraceae & $\mathrm{H}$ & sredeu \\
\hline Buphthalmum salicifolium L. & Asteraceae & $\mathrm{H}$ & sredeu \\
\hline Carduus acanthoides L. & Asteraceae & $\mathrm{H}$ & jeu \\
\hline Carlina acanthifolia All. & Asteraceae & $\mathrm{H}$ & jeu \\
\hline Carlina vulgaris L. & Asteraceae & $\mathrm{H}$ & euroaz \\
\hline
\end{tabular}


D. Zima, E. Štefanić, V. Kovačević: Florni sastav suhog travnjaka na području Rudine Zbornik Veleučilišta u Rijeci, Vol. 7 (2019), No. 1, pp. 411-424

\begin{tabular}{|c|c|c|c|}
\hline Carlina vulgaris L. ssp. intermedia(Schur) Hayek & Asteraceae & $\mathrm{H}$ & jieu \\
\hline Centaurea nigrescens Willd. & Asteraceae & $\mathrm{H}$ & jeu \\
\hline Centaurea scabiosa L. & Asteraceae & $\mathrm{H}$ & euroaz \\
\hline Cirsium arrvense (L.) Scop. & Asteraceae & G & euroaz \\
\hline Erigeron annuus (L.) Pers. & Asteraceae & $\mathrm{H}$ & adv \\
\hline Eupatorium cannabinum L. & Asteraceae & $\mathrm{H}$ & euroaz \\
\hline Inula salicina $\mathrm{L}$. & Asteraceae & $\mathrm{H}$ & euroaz \\
\hline Leucanthemum vulgare Lam. & Asteraceae & $\mathrm{H}$ & šir \\
\hline Matricaria perforata Merat. & Asteraceae & $\mathrm{T}$ & šir \\
\hline Senecio erucifolius L. ssp. tenuifolius Schübl. et G.Martens & Asteraceae & $\mathrm{H}$ & euroaz \\
\hline Solidago canadensis L. & Asteraceae & $\mathrm{H}$ & adv \\
\hline Solidago virgaurea $\mathrm{L}$. & Asteraceae & $\mathrm{H}$ & euroaz \\
\hline Xeranthemum cylindraceum Sibt. et Sm. & Asteraceae & $\mathrm{T}$ & jeu \\
\hline Anthoxanthum odoratum L. & Poaceae & $\mathrm{H}$ & euroaz \\
\hline Arrhenatherum elatius (L.) P. Beauv. ex J. Presl et C. Presl & Poaceae & $\mathrm{H}$ & $\mathrm{eu}$ \\
\hline Brachypodium pinnatum (L.) P.Beauv. & Poaceae & $\mathrm{H}$ & euroaz \\
\hline Brachypodium sylvaticum (Huds.) P. Beauv. & Poaceae & $\mathrm{H}$ & euroaz \\
\hline Briza media L. & Poaceae & $\mathrm{T}$ & euroaz \\
\hline Bromus hordeaceus $\mathrm{L}$. & Poaceae & $\mathrm{T}$ & šir \\
\hline Bromus racemosus $\mathrm{L}$. & Poaceae & $\mathrm{T}$ & šir \\
\hline Bromus squarrosus L. & Poaceae & $\mathrm{T}$ & jeu \\
\hline Bromus sterilis L. & Poaceae & $\mathrm{T}$ & šir \\
\hline Calamagrostis epigejos (L.) Roth & Poaceae & $\mathrm{H}$ & eu \\
\hline Dactylis glomerata L. & Poaceae & $\mathrm{H}$ & euroaz \\
\hline Dichanthium ischaemum (L.) Roberty & Poaceae & $\mathrm{H}$ & jeu \\
\hline Elymus hispidus (Opiz) Melderis & Poaceae & $\mathrm{H}$ & jeu \\
\hline Festuca ovina L. & Poaceae & $\mathrm{H}$ & cirkumhol \\
\hline Festuca pseudovina Hack. ex Wiesb. & Poaceae & $\mathrm{H}$ & ieup \\
\hline Festuca rupicola Heuff. & Poaceae & $\mathrm{H}$ & jieu \\
\hline Festuca valesiaca Schleich. ex Gaudin & Poaceae & $\mathrm{H}$ & jeu \\
\hline Holcus lanatus L. & Poaceae & $\mathrm{H}$ & euroaz \\
\hline Lolium perenne $\mathrm{L}$. & Poaceae & $\mathrm{H}$ & eu \\
\hline Poa compressa L. & Poaceae & $\mathrm{H}$ & šir \\
\hline Anthyllis vulneraria L. ssp. polyphylla (DC.) Nyman. & Fabaceae & $\mathrm{H}$ & jeu \\
\hline Astragalus glycyphyllos L. & Fabaceae & $\mathrm{H}$ & ieup \\
\hline
\end{tabular}



Zbornik Veleučilišta u Rijeci, Vol. 7 (2019), No. 1, pp. 411-424

\begin{tabular}{|c|c|c|c|}
\hline Coronilla varia $\mathrm{L}$. & Fabaceae & $\mathrm{H}$ & eu \\
\hline Dorycnium herbaceum Vill. & Fabaceae & $\mathrm{Ch}$ & jeu \\
\hline Genista pilosa L. & Fabaceae & $\mathrm{Ch}$ & at \\
\hline Lathyrus aphaca L. & Fabaceae & $\mathrm{T}$ & jeu \\
\hline Lathyrus latifolius L. & Fabaceae & $\mathrm{H}$ & jeu \\
\hline Lathyrus pratensis $\mathrm{L}$. & Fabaceae & $\mathrm{H}$ & euroaz \\
\hline Lembotropis nigricans, (L.) Griseb. & Fabaceae & $\mathrm{Ch}$ & jeu \\
\hline Lotus corniculatus L. & Fabaceae & $\mathrm{H}$ & šir \\
\hline Medicago falcata $\mathrm{L}$. & Fabaceae & $\mathrm{H}$ & euroaz \\
\hline Medicago lupulina L. & Fabaceae & $\mathrm{H}$ & šir \\
\hline Medicago minima (L.) Bartal. & Fabaceae & $\mathrm{T}$ & šir \\
\hline Medicago sativa $\mathrm{L}$. & Fabaceae & $\mathrm{H}$ & šir \\
\hline Melilotus officinalis (L.) Lam. & Fabaceae & $\mathrm{H}$ & euroaz \\
\hline Trifolium campestre Schreber & Fabaceae & $\mathrm{H}$ & šir \\
\hline Trifolium dubium Sibth. & Fabaceae & $\mathrm{T}$ & jeu \\
\hline Trifolium pratense L. & Fabaceae & $\mathrm{H}$ & euroaz \\
\hline Trifolium repens $\mathrm{L}$. & Fabaceae & $\mathrm{H}$ & šir \\
\hline Agrimonia eupatoria L. & Rosaceae & $\mathrm{H}$ & cirkumhol \\
\hline Filipendula vulgaris Moench & Rosaceae & $\mathrm{H}$ & euroaz \\
\hline Fragaria moschata Duchesne & Rosaceae & $\mathrm{H}$ & sredeu \\
\hline Fragaria vesca $\mathrm{L}$ & Rosaceae & $\mathrm{H}$ & euroaz \\
\hline Fragaria viridis Duchesne & Rosaceae & $\mathrm{H}$ & euroaz \\
\hline Potentilla argentea L. & Rosaceae & $\mathrm{H}$ & šir \\
\hline Potentilla reptans $\mathrm{L}$. & Rosaceae & $\mathrm{H}$ & šir \\
\hline Prunus avium L. & Rosaceae & $\mathrm{P}$ & euroaz \\
\hline Prunus spinosa $\mathrm{L}$. & Rosaceae & $P$ & euroaz \\
\hline Pyrus pyraster (L.) Burgsd. & Rosaceae & $P$ & euroaz \\
\hline Rosa arvensis Huds. & Rosaceae & $P$ & sredeu \\
\hline Rosa canina $\mathrm{L}$. & Rosaceae & $P$ & euroaz \\
\hline Rubus caesius L. & Rosaceae & $P$ & euroaz \\
\hline Rubus plicatus Weihe et Nees & Rosaceae & $\mathrm{P}$ & sredeu \\
\hline Sanguisorba minor Scop. ssp. muricata Briq. & Rosaceae & $\mathrm{H}$ & jeu \\
\hline Clinopodium vulgare L. & Lamiaceae & $\mathrm{H}$ & šir \\
\hline Mentha longifolia (L.) Huds. & Lamiaceae & $\mathrm{H}$ & šir \\
\hline Prunella laciniata (L.) L. & Lamiaceae & $\mathrm{H}$ & jeu \\
\hline
\end{tabular}


D. Zima, E. Štefanić, V. Kovačević: Florni sastav suhog travnjaka na području Rudine Zbornik Veleučilišta u Rijeci, Vol. 7 (2019), No. 1, pp. 411-424

\begin{tabular}{|c|c|c|c|}
\hline Prunella vulgaris $\mathrm{L}$. & Lamiaceae & $\mathrm{H}$ & euroaz \\
\hline Salvia pratensis $\mathrm{L}$. & Lamiaceae & $\mathrm{H}$ & $\mathrm{eu}$ \\
\hline Salvia verticillata $\mathrm{L}$. & Lamiaceae & $\mathrm{H}$ & jeu \\
\hline Stachys recta L. & Lamiaceae & $\mathrm{H}$ & jeu \\
\hline Teucrium chamaedrys L. & Lamiaceae & $\mathrm{Ch}$ & jeu \\
\hline Thymus pulegioides $\mathrm{L}$. & Lamiaceae & $\mathrm{Ch}$ & jeu \\
\hline Thymus serpyllum L. & Lamiaceae & $\mathrm{Ch}$ & $\mathrm{eu}$ \\
\hline Cichorium intybus L. & Cichoriaceae & $\mathrm{T}$ & šir \\
\hline Chondrilla juncea $\mathrm{L}$. & Cichoriaceae & $\mathrm{H}$ & euroaz \\
\hline Crepis tectorum $\mathrm{L}$. & Cichoriaceae & $\mathrm{H}$ & euroaz \\
\hline Hieracium pilosella $\mathrm{L}$. & Cichoriaceae & $\mathrm{H}$ & euroaz \\
\hline $\begin{array}{l}\text { Hieracium praealtum Vill. ex Gochnat ssp. } \\
\text { bauhinii (Besser) Petunn. }\end{array}$ & Cichoriaceae & $\mathrm{H}$ & euroaz \\
\hline Leontodon hispidus ssp. danubialis(Jacq.) Simonk. & Cichoriaceae & $\mathrm{H}$ & sredeu \\
\hline Picris hieracioides L. & Cichoriaceae & $\mathrm{H}$ & euroaz \\
\hline Tragopogon dubius Scop. & Cichoriaceae & $\mathrm{H}$ & jeu \\
\hline Asperula cynanchica L. & Rubiaceae & $\mathrm{H}$ & jeu \\
\hline Galium aparine L. & Rubiaceae & $\mathrm{T}$ & šir \\
\hline Galium lucidum All. & Rubiaceae & $H$ & jeu \\
\hline Galium mollugo L. & Rubiaceae & $\mathrm{H}$ & euroaz \\
\hline Galium verum $\mathrm{L}$. & Rubiaceae & $\mathrm{H}$ & šir \\
\hline Sherardia arvensis L. & Rubiaceae & $\mathrm{T}$ & šir \\
\hline Arenaria serpyllifolia L. & Caryophyllaceae & $\mathrm{T}$ & šir \\
\hline $\begin{array}{l}\text { Cerastium fontanum Baumg. ssp. vulgare } \\
\text { (Hartman) Greuter et Burdet }\end{array}$ & Caryophyllaceae & $\mathrm{Ch}$ & šir \\
\hline Dianthus armeria L. & Caryophyllaceae & $\mathrm{T}$ & $\mathrm{eu}$ \\
\hline Petrorhagia prolifera (L.) P. W. Ball \& Heywood & Caryophyllaceae & $\mathrm{T}$ & euroaz \\
\hline Silene vulgaris (Moench) Garcke & Caryophyllaceae & $\mathrm{H}$ & jeu \\
\hline Dipsacus laciniatus L. & Dipsacaceae & $\mathrm{H}$ & euroaz \\
\hline Knautia arvensis (L.) Coult. & Dipsacaceae & $\mathrm{H}$ & euroaz \\
\hline Knautia drymeia Heuff. & Dipsacaceae & $\mathrm{H}$ & jeu \\
\hline $\begin{array}{l}\text { Knautia drymeia Heuff. ssp. } \\
\text { intermedia (Pernh. et Wettst.) Ehrend. }\end{array}$ & Dipsacaceae & $\mathrm{H}$ & jeu \\
\hline Scabiosa ochroleuca L. & Dipsacaceae & $\mathrm{H}$ & ieup \\
\hline Digitalis grandiflora Mill. & Scrophulariaceae & $\mathrm{H}$ & jeu \\
\hline Melampyrum arvense L. & Scrophulariaceae & $\mathrm{T}$ & euroaz \\
\hline
\end{tabular}



Zbornik Veleučilišta u Rijeci, Vol. 7 (2019), No. 1, pp. 411-424

\begin{tabular}{|c|c|c|c|}
\hline Rhinanthus minor $\mathrm{L}$. & Scrophulariaceae & $\mathrm{T}$ & 10 \\
\hline Verbascum phlomoides $\mathrm{L}$. & Scrophulariaceae & $\mathrm{H}$ & eu \\
\hline $\begin{array}{l}\text { Veronica teucrium L. ssp. pseudochamaedrys } \\
\text { (Jacq.) Nyman }\end{array}$ & Scrophulariaceae & $\mathrm{Ch}$ & cirkumhol \\
\hline Daucus carota L. & Apiaceae & $\mathrm{H}$ & euroaz \\
\hline Eryngium campestre $\mathrm{L}$. & Apiaceae & $\mathrm{H}$ & jeu \\
\hline Pimpinella saxifraga $\mathrm{L}$. & Apiaceae & $\mathrm{H}$ & euroaz \\
\hline Seseli annuum L. & Apiaceae & $\mathrm{H}$ & euroaz \\
\hline Tordylium maximum L. & Apiaceae & $\mathrm{H}$ & jeu \\
\hline Anchusa officinalis L. & Boraginaceae & $\mathrm{H}$ & $\mathrm{eu}$ \\
\hline Echium vulgare $\mathrm{L}$. & Boraginaceae & $\mathrm{H}$ & $\mathrm{eu}$ \\
\hline Myosotis stricta Link ex Roem. et Schult. & Boraginaceae & $\mathrm{T}$ & euroaz \\
\hline Myosotis sylvatica Hoffm. & Boraginaceae & $\mathrm{H}$ & euroaz \\
\hline Clematis vitalba $\mathrm{L}$. & Ranunculaceae & $P$ & eu \\
\hline Helleborus odorus Waldst. et Kit. ex Willd. & Ranunculaceae & $\mathrm{H}$ & jieu \\
\hline Ranunculus acris $\mathrm{L}$. & Ranunculaceae & $\mathrm{H}$ & šir \\
\hline Ranunculus bulbosus L. & Ranunculaceae & $\mathrm{G}$ & euroaz \\
\hline Carex divulsa Stokes & Cyperaceae & $\mathrm{H}$ & šir \\
\hline Carex flacca Schreb. & Cyperaceae & $G$ & šir \\
\hline Carex pendula Huds. & Cyperaceae & $\mathrm{H}$ & euroaz \\
\hline Carex sylvatica Huds. & Cyperaceae & $\mathrm{H}$ & $\mathrm{eu}$ \\
\hline Alyssum alyssoides (L.) L. & Brassicaceae & $\mathrm{T}$ & jeu \\
\hline Capsella bursa pastoris (L.) Medik & Brassicaceae & $\mathrm{T}$ & šir \\
\hline Conringia orientalis (L.) Dumort & Brassicaceae & $\mathrm{T}$ & jeu \\
\hline Campanula bononiensis $\mathrm{L}$. & Campanulaceae & $\mathrm{H}$ & euroaz \\
\hline Campanula patula L. & Campanulaceae & $\mathrm{H}$ & $\mathrm{eu}$ \\
\hline Campanula persicifolia L. & Campanulaceae & $\mathrm{H}$ & euroaz \\
\hline Castanea sativa Mill. & Fagaceae & $\mathrm{P}$ & jeu \\
\hline Quercus petraea (Matt.) Liebl. & Fagaceae & $\mathrm{P}$ & eu \\
\hline Quercus pubescens Willd. & Fagaceae & $\mathrm{P}$ & jeu \\
\hline Linum cathariticum $\mathrm{L}$. & Linaceae & $\mathrm{T}$ & šir \\
\hline Linum flavum $\mathrm{L}$. & Linaceae & $\mathrm{H}$ & ieup \\
\hline Linum hirsutum L. & Linaceae & $\mathrm{H}$ & ieup \\
\hline Anacamptis pyramidalis (L.) Rich. & Orchidaceae & $G$ & $\mathrm{eu}$ \\
\hline Orchis morio L. & Orchidaceae & G & euroaz \\
\hline
\end{tabular}


D. Zima, E. Štefanić, V. Kovačević: Florni sastav suhog travnjaka na području Rudine Zbornik Veleučilišta u Rijeci, Vol. 7 (2019), No. 1, pp. 411-424

\begin{tabular}{|c|c|c|c|}
\hline Orchis tridentata Scop. & Orchidaceae & $G$ & jeu \\
\hline Carpinus betulus L. & Corylaceae & $\mathrm{P}$ & sredeu \\
\hline Corylus avellana $\mathrm{L}$. & Corylaceae & $P$ & eu \\
\hline Calystegia sepium (L.) R. Br. & Convolvulaceae & $\mathrm{G}$ & šir \\
\hline Convolvulus arvensis $\mathrm{L}$. & Convolvulaceae & $\mathrm{H}$ & šir \\
\hline Geranium columbinum L. & Geraniaceae & $\mathrm{T}$ & euroaz \\
\hline Geranium dissectum $\mathrm{L}$. & Geraniaceae & $\mathrm{T}$ & šir \\
\hline Fraxinus ornus L. & Oleaceae & $\mathrm{P}$ & jeu \\
\hline Ligustrum vulgare L. & Oleaceae & $\mathrm{P}$ & sredeu \\
\hline Plantago lanceolata $\mathrm{L}$. & Plantaginaceae & $\mathrm{H}$ & šir \\
\hline Plantago media L. & Plantaginaceae & $\mathrm{H}$ & euroaz \\
\hline Rumex acetosa $\mathrm{L}$. & Polygonaceae & $\mathrm{H}$ & šir \\
\hline Rumex crispus L. & Polygonaceae & $\mathrm{H}$ & šir \\
\hline Populus tremula L. & Salicaceae & $\mathrm{P}$ & euroaz \\
\hline Salix capraea L. & Salicaceae & $P$ & euroaz \\
\hline Saxifraga adscendens L. & Saxifragaceae & $\mathrm{T}$ & euroaz \\
\hline Saxifraga tridactylites $\mathrm{L}$. & Saxifragaceae & $\mathrm{T}$ & šir \\
\hline Allium schoenoprasum (L.) Rich. & Liliaceae & $\mathrm{G}$ & ieup \\
\hline Allium vineale $\mathrm{L}$. & Liliaceae & $\mathrm{G}$ & šir \\
\hline Acer campestre & L.Aceraceae & $\mathrm{P}$ & eu \\
\hline Acer tataricum $\mathrm{L}$. & Aceraceae & $P$ & $\mathrm{eu}$ \\
\hline Asclepias syriaca $\mathrm{L}$. & Asclepiadaceae & $\mathrm{H}$ & adv \\
\hline Vincetoxicum hirundinaria Medik & Asclepiadaceae & $\mathrm{H}$ & euroaz \\
\hline Betula pendula Roth. & Betulaceae & $P$ & euroaz \\
\hline Humulus lupulus L. & Cannabaceae & $\mathrm{H}$ & euroaz \\
\hline $\begin{array}{l}\text { Helianthemum nummularium (L.) Mill. ssp. } \\
\text { obscurum (Čelak.) Holub }\end{array}$ & Cistaceae & $\mathrm{Ch}$ & jeu \\
\hline Hypericum perforatum L. & Clusiaceae & $\mathrm{H}$ & šir \\
\hline Cornus sanguinea $\mathrm{L}$. & Cornaceae & $\mathrm{P}$ & eu \\
\hline Sedum acre L. & Crassulaceae & $\mathrm{Ch}$ & euroaz \\
\hline Cuscuta europaea L. & Cuscutaceae & $\mathrm{T}$ & euroaz \\
\hline Euphorbia cyparissias L. & Euphorbiaceae & $\mathrm{H}$ & euroaz \\
\hline Gentianella ciliata (L.) Borkh. & Gentianaceae & $\mathrm{H}$ & euroaz \\
\hline Epilobium tetragonum L. ssp. lamyi (F. W. Schultz) Nyman & Onagraceae & $\mathrm{H}$ & $\mathrm{eu}$ \\
\hline Orobanche caryophyllacea Sm. & Orobanchaceae & G & euroaz \\
\hline
\end{tabular}




\begin{tabular}{|lccc|}
\hline Urtica dioica L. & Urticaceae & $\mathrm{H}$ & šir \\
\hline Valeriana officinalis L. & Valerianaceae & $\mathrm{H}$ & euroaz \\
\hline Vitis vinifera L. ssp. sylvestris (C. C. Gmel.) Hegi & Vitaceae & $\mathrm{P}$ & jeu \\
\hline Juniperus communis L. & Cupressaceae & $\mathrm{P}$ & cirkumhol \\
\hline Pinus sylvestris L. & Pinaceae & $\mathrm{P}$ & euroaz \\
\hline
\end{tabular}

Taksonomska analiza pokazala je da su sve zabilježene vrste svrstane u 46 porodica i 134 rodova. 40 porodica je unutar dvosupnica, a samo 4 porodice unutar jednosupnica (tablica 2).

Tablica 2. Taksonomska analiza flore

\begin{tabular}{|l|c|c|c|}
\hline & Porodica & Rod & Vrsta \\
\hline Sjemenjače (Spermatophyta) & & & 2 \\
\hline Golosjemenjače (Gymnospermae) & 2 & 2 & 155 \\
\hline Kritosjemenjače (Angiospermae) & & & 29 \\
\hline Dvosupnice (Dicotyledones) & 40 & 115 & 186 \\
\hline Jednosupnice (Monocotyledones) & 4 & 17 & 134 \\
\hline Ukupno & 46 & & \\
\hline
\end{tabular}

Vrstama najbrojnije porodice su Asteraceae s 23 vrste (12,37 \%) i Poaceae s 20 vrsta (10,75 \%), a velikim brojem vrsta još se ističu Fabaceae s 19 vrsta (10,2\%), Rosaceae s 15 vrsta (8,1 \%) i Lamiaceae s 10 vrsta (5,4\%). Ostale porodice zastupljene su manjim brojem vrsta (grafikon 1). Navedene porodice najbrojnije su vrstama i u istraživanjima suhih travnjaka koje su proveli Zima, Stefanic (2009) i Krstonošić et al. (2016) koji navode da do porasta udjela trava dolazi nakon napuštanja staništa, a vezano je za staništa južnih i termofilnijih izloženosti i potaknuto nedostatkom ispaše. 


\section{Grafikon 1. Broj vrsta prema porodicama}

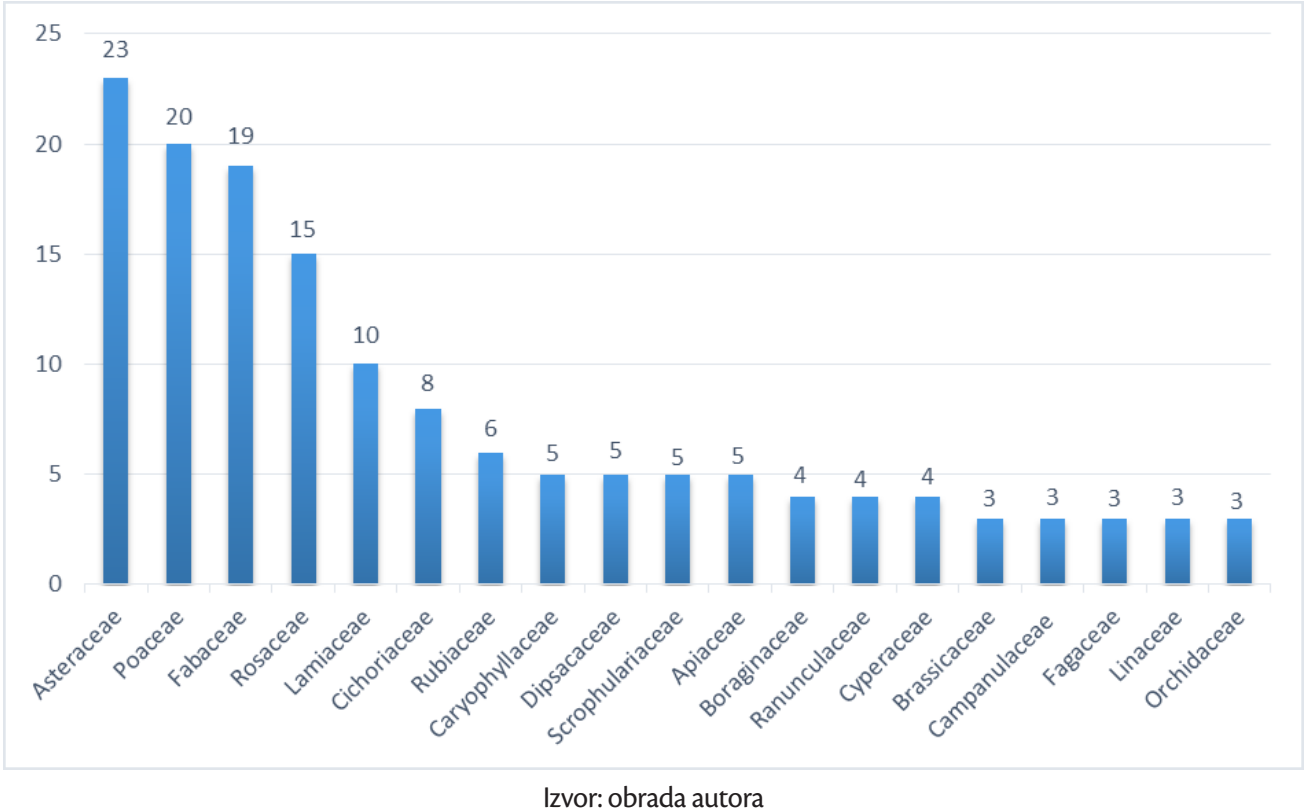

Analiza životnih oblika pokazala je da su najzastupljeniji Hemicryptophyta sa 113 vrsta (60,8 \%), Therophyta s 29 vrsta (15,6\%), a nakon njih slijede Phanerophyta s 24 vrste (12,9\%) te Geophyta i Chamaephyta s 10 vrsta (5,4\%) (grafikon 2). I u istraživanjima Zima, Stefanic (2009) te Krstonošić et al. (2016) utvrđena je dominacija Hemicryptophyta, što je i tipično za travnjake. Visoki udio Phanerophyta (12,9\%) dokaz je uznapredovale sukcesije vegetacije na istraživanom području.

Grafikon 2. Životni oblici

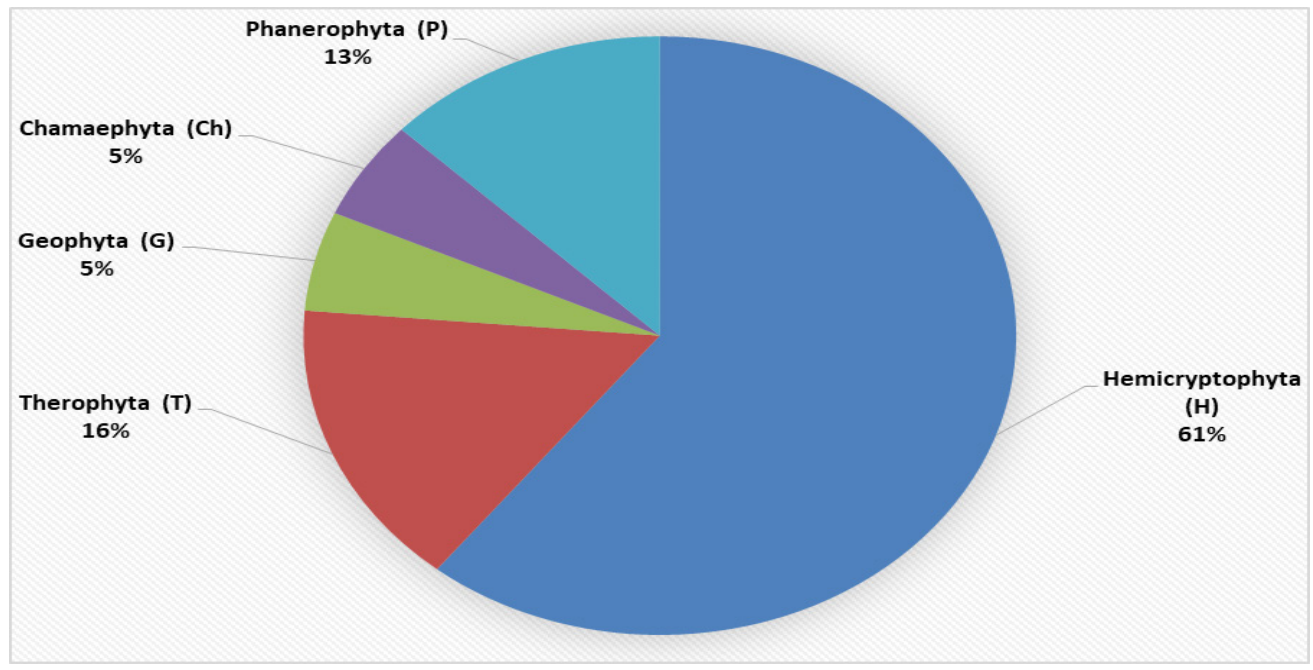

Izvor: obrada autora 
Fitogeografska analiza flore ukazala je na najveću zastupljenost biljaka euroazijskog flornog elementa koji je zastupljen sa 63 vrste (33,9\%). Nakon njega slijede biljke široke rasprostranjenosti s 38 vrsta (20,4\%), biljke južnoeuropskog flornog elementa s 37 vrsta (19,9\%) i biljke europskog flornog elementa s $20 \mathrm{vrsta}(10,8 \%$ ). Treba istaći i biljke srednjoeuropskog flornog elementa s $9 \mathrm{vrsta}$ (4,8\%), istočnoeuropsko-pontskog flornog elementa sa 6 vrsta (3,2 \%), biljke cirkumholarktičke rasprostranjenosti s 5 vrsta (2,7\%), kultivirane i adventivne biljke s 4 vrste (2,2\%), biljke jugoistočnoeuropskog flornog elementa s 3 vrste $(1,6 \%)$ i atlantskog flornog elementa s jednom vrstom (0,5\%) (grafikon 3).

Grafikon 3. Fitogeografska analiza flore

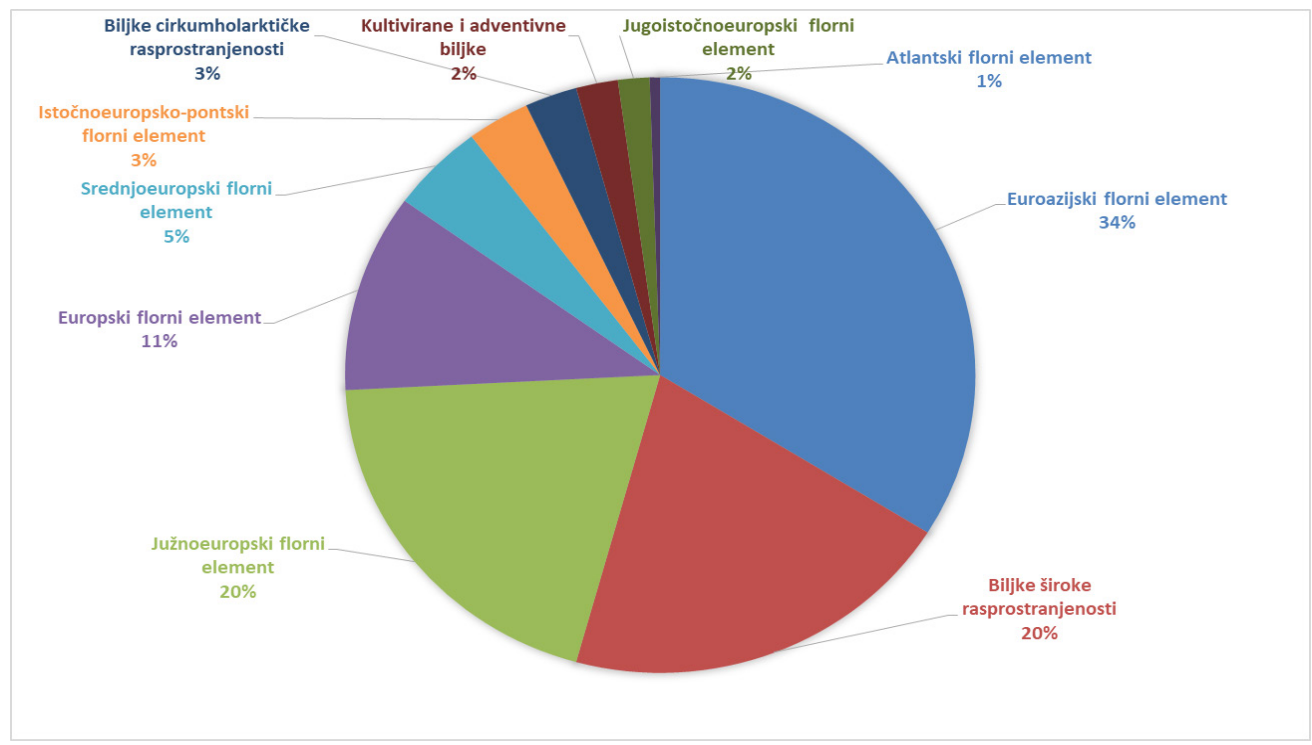

Izvor: obrada autora

Prema popisu ugroženih vrsta u Crvenoj knjizi biljnih vrsta Republike Hrvatske (Nikolić, Topić, 2005) nijedna od navedenih vrsta nije ugrožena. Provedena je fitocenološka analiza florističkog sastava za biljne svojte razvrstavane po njihovoj vezanosti za određene sintaksonomske jedinice prema Simonu (2000). Prema toj analizi razmjerno najveći broj svojta su karakteristične (svojstvene) vrste razreda Festuco-Brometea, npr. Anthyllis vulneraria, Asperula cynanchica, Lathyrus latifolius, Brachypodium pinnatum, Scabiosa ochroleuca, Festuca rupicola, Anacamptis pyramidalis i dr., no potrebno je istaći i prilično veliku zastupljenost karakterističnih svojta zajednica razreda MolinioArrhenatheretea te velik udio termofilnih vrsta iz razreda Quercion pubescentis-petraeae, kao i iz razreda Querco-Fagetea. U okviru razreda Festuco-Brometea određeni broj vrsta karakterističan je za red Festucetalia valesiacae, npr: Festuca rupicola, Festuca valesiaca, Asperula cynanchica, Stachys recta, Galium verum, Dichanthium ischaemum, Fragaria viridis, Achillea collina i dr. Red Brometalia erecti zastupljen je vrstama: Brachypodium pinnatum, Briza media, Anthyllis vulneraria, Orchis tridentata, Anacamptis pyramidalis, Plantago media, Trifolium montanum i dr. Razredu MolinioArrhenatheretea pripadaju sljedeće vrste: Trifolium pratense, Lotus corniculatus, Plantago lanceolata, 


\section{Zima, E. Štefanić, V. Kovačević: Florni sastav suhog travnjaka na području Rudine Zbornik Veleučilišta u Rijeci, Vol. 7 (2019), No. 1, pp. $411-424$}

Leucanthemum vulgare, Prunella vulgaris i dr. Termofilne vrste razreda Quercion pubescentispetraeae su npr:: Fraxinus ornus, Vincetoxicum hirundinaria, Quercus pubescens, Clinopodium vulgare i dr. Razredu Querco-Fagetea pripadaju vrste: Clematis vitalba, Cornus sanguinea, Prunus spinosa i dr. (Topić, llijanić, 2007; Horvat, 1962; Topić, Vukelić, 2009). Fitocenološka analiza florističkog sastava ukazuje da ovaj prijelazni karakter travnjaka odražava lokalne ekološke značajke staništa kao i prijelazni fitogeografski položaj područja (Topić, llijanić, 2007).

\section{ZAKLJUČAK}

Rezultati florističkih istraživanja pokazuju da je na travnjaku Rudine zabilježeno 186 svojta vaskularne flore u okviru 46 porodica i 134 rodova. $S$ obzirom na broj najzastupljenije su porodice Asteraceae s 23 vrste (12,4\%) i Poaceae s 20 vrsta (10,8\%). Analiza životnih oblika pokazuje da su hemikriptofiti sa 113 vrsta (60,8 \%) najzastupljeniji životni oblik. Fitogeografska analiza ukazuje na dominantnu prisutnost euroazijskog flornog elementa sa 63 vrste (33,9\%), biljaka široke rasprostranjenosti s 38 vrsta (20,4 \%) te veliku zastupljenost biljaka južnoeuropskog flornog elementa s 37 vrsta (19,9\%). Istraživani travnjak čini prijelazni položaj između razreda Festuco-Brometea i Molinio-Arrhenatheretea, odnosno pokazuje prijelazni položaj između redova Festucetalia valesiacae, Brometalia erecti i Arrhenatheretalia. Kao i većinu travnjaka i ovaj je potrebno kontinuirano floristički istraživati, posebice stoga što se nalazi u prirodnoj sukcesiji i prijeti mu nestanak. Velik broj zabilježenih biljnih vrsta na ovom travnjaku dokazuje veliku bioraznolikost, a njegovo zarastanje bi je u bitnome smanjilo. S obzirom na blizinu povijesnog lokaliteta, preporuka bi bila održavati ovaj travnjak ispašom, košnjom i mehaničkim uklanjanjem drvenastih vrsta, točnije, kombinirati biološko-mehaničke metode održavanja travnjaka.

\section{LITERATURA}

Domac, R. (1994) Flora Hrvatske, Školska knjiga, Zagreb

Horvat, I. (1949) Nauka o biljnim zajednicama, Nakladni zavod Hrvatske, Zagreb

Horvat, I. (1962) Vegetacija planina zapadne Hrvatske, Acta biol. 2, 30:1-179, Zagreb

Horvatić, S. (1963) Vegetacijska karta otoka Paga s općim pregledom vegetacijskih jedinica Hrvatskog primorja. Acta biologica 4

Horvatić, S., Ilijanić, Lj., Marković-Gospodnetić, Lj. (1967-1968) Biljni pokrov okolice Senja, Senjski zbornik 3: p. 298-322

Horvatić, S., Trinajstić, I. (eds.), (1967-1981) Analitička flora Jugoslavije 1, Zagreb

Ilijanić, Lj. (1977) O biljnom pokrovu Požeške kotline. Požega 1277-1977, p. 48-65, Požega

Josifović, M. (eds.) (1971-1976) Flora SR Srbije 1-8, Srpska akademija nauka i umetnosti, Beograd

Kovačević, J. (1974) Biljni pokrov Požeške kotline, Požeški zbornik IV: p. 175-180

Krstonošić, D., Guzmić, M., Franjić, J., Škvorc, Ž., Sever, K. (2016) Flora termofilnih travnjaka u sukcesiji na južnim obroncima Papuka, Glasnik Hrvatskog botaničkog društva, 4 (1), p. 4-21

Nikolić T. ur. (2018). Flora Croatica Database (URL http://hirc.botanic.hr/fcd). Prirodoslovno-matematički fakultet, Sveučilište u Zagrebu 
Nikolić, T., Topić, J. (ur.) (2005) Crvena knjiga vaskularne flore Republike Hrvatske. Ministarstvo kulture, Državni zavod za zaštitu prirode. Zagreb

Pignatti, S. (1982) Flora d Italia vol 1-3. Edagriole, Bologna

Rauš, Đ., Šegulja, N. (1983) Flora Slavonije i Baranje. Glas. za šum. pokuse 21: p. 179-211

Šegulja, N. (1977) Analiza flore Vukomeričkih gorica. Biosistematika 3 (1), p. 45-59

Simon, T. (2000) A magyarországi edényes flóra határozója. Nemzeti Tankönyvkiadó, Budapest. 976 pp

Tomašević, M. (1998) Prilog flori Požžǩke kotline i okolnoga gorja. Acta Bot. Croat. 55/56: p. 119-131

Tomašević, M. (1998) The analysis of the flora oft he Požega Valley and surrounding mountains. Nat. Croat. 7(3), p. 227-274

Tomašević, M. (2006) A new contribution to the flora of the Požega Valley and the surrounding mountains. Nat. Croat. 15(1-2): p. 43-60

Tomašević, M. (2016) Flora Požeške kotline i Slavonskog gorja, HAZU, Zavod za znanstveni i umjetnički rad u Požegi, Zagreb-Požega

Topić, J., llijanić, Lj. (2007) Biljnogeografske i florističko - fitocenološke značajke suhih travnjaka u Parku prirode Papuk. Javna ustanova Park prirode Papuk 1-9

Topić, J., Vukelić, J. (2009) Priručnik za određivanje kopnenih staništa u Hrvatskoj prema direktivi o staništima u EU. Državni zavod za zaštitu prirode, Zagreb

Trinajstić, I. (eds.) (1975.-1986) Analitička flora Jugoslavije 2. Institut za botaniku Sveučilišta u Zagrebu

Tutin, T. G., Heywood, V. H., Burges, N. A., Moore, D. M., Valentine, D. H., Walters, S. M., Webb, D. A. (1964-1980): Flora Europaea 1-5. Cambridge University Press. Cambridge

Zima, D. (2008) Vegetacija suhih travnjaka Požeške kotline. Magistarski rad. Sveučilište Josipa Jurja Strossmayera u Osijeku. Osijek

Zima, D., Štefanić, E. (2009a): “Suhi travnjaci i mogućnosti njihove zaštite”. Zbornik radova 44. Hrvatski i 4. međunarodni simpozij agronoma, Poljoprivredni fakultet u Osijeku, Osijek, p. 122-126

Zima, D., Štefanić, E. (2009b): Florističke značajke suhih travnjaka Požě̌ke kotline, Agronomski glasnik, 2, p. 141-150 


\title{
FLORISTIC COMPOSITION OF DRY GRASSLANDS IN THE AREA OF RUDINE
}

\author{
Dinko Zima \\ PhD, College Professor, Polytechnic in Požega, Vukovarska 17, 34000 Požega, Croatia; e-mail: dzima@vup.hr \\ Edita Štefanić \\ PhD, Full Professor, Faculty of Agrobiotechnical Sciences Osijek, Vladimira Preloga 1, 31000 Osijek, Croatia; \\ e-mail: estefanic@pfos.hr \\ Vesna Kovačević \\ PhD, Senior Lecturer, Polytechnic of Rijeka, Vukovarska 58, 51000 Rijeka, Croatia; \\ e-mail:vesna.kovacevic@veleri.hr
}

\begin{abstract}
On gentle eastern slopes of Psunj, dry grasslands are developed. Dry grasslands represent one of the most endangered forms of vegetation, and were the subject of this research. The terrain is slightly sloping towards the southeast, southern exposure, altitude about $400 \mathrm{~m}$. The aim of the research was to determine the abundance and variety of vascular flora of grasslands in Rudine area. Floristic research was conducted in 2003, 2008, 2016 and 2017. On the surface of about $2500 \mathrm{m2}$, a list of plant taxa has been compiled and determined by their affiliation with families, floral elements and life forms. One hundred and eighty-six vascular plants of 46 families and 134 genera were recorded. Taxonomic, ecological and phytogeological analysis was carried out. Taxonomic analysis suggests there are 2 species of gymnosperm (1.08\%), 155 species of dicotyledons (83.33\%), and 29 species of monocotyledons (15.59\%). The analysis of life forms shows that the most represented are 113 species of hemicryptophytes (60.75\%), and 29 species of terophytes (15.59\%). Plants of the Eurasian floral element with 63 species (33.87\%) and plants with a wide spread of 38 species (20.43\%) dominate in phytogeographic analysis. The phytocenological analysis of floristic composition shows that these grasslands are a transient position between the Festuco-Brometea and Molinio-Arrhenatheretea classes, that is to show the transition between Festucetalia valesiacae, Brometalia erecti and Arrhenatheretalia.
\end{abstract}

Key words: Rudina, dry grasslands, floristic composition 